\title{
ReaxFF molecular dynamics simulations of $\mathrm{CO}$ collisions on an O-preadsorbed silica surface
}

\author{
Pablo Gamallo, Hèctor Prats and Ramón Sayós * \\ Departament de Química Física and Institut de Química Teòrica i Computacional (IQTC-UB), Univ. Barcelona, \\ C. Martí i Franquès 1, 08028 Barcelona (Spain)
}

\begin{abstract}
A quasiclassical trajectory dynamics study was performed for carbon monoxide collisions over an oxygen preadsorbed $\beta$-cristobalite (001) surface. A reactive molecular force field (ReaxFF) was used to model the potential energy surface. The collisions were performed fixing several initial conditions: CO rovibrational states $(\mathrm{v}=0-5$ and $\mathrm{j}=0,20,35)$, collision energies $\left(0.05 \leq \mathrm{E}_{\mathrm{col}} \leq 2.5 \mathrm{eV}\right)$, incident angles $\left(\theta_{\mathrm{v}}=0^{\circ}, 45^{\circ}\right)$ and surface temperatures $\left(\mathrm{T}_{\text {surf }}=300 \mathrm{~K}, 900 \mathrm{~K}\right)$. The principal elementary processes were the molecular reflection and the non-dissociative molecular adsorption. $\mathrm{CO}_{2}$ molecules were also formed in minor extension via an Eley-Rideal reaction although some of them were finally retained on the surface. The scattered $\mathrm{CO}$ molecules tend to be translationally colder and internally hotter (rotationally and vibrationally) than the initial ones. The present study supports that $\mathrm{CO}+\mathrm{O}_{\mathrm{ad}}$ reaction should be less important than $\mathrm{O}+\mathrm{O}_{\mathrm{ad}}$ reaction over silica for similar initial conditions of reactants, in agreement with experimental data.
\end{abstract}

Keywords: Quasiclassical trajectories, Mars atmosphere, Eley-Rideal reaction, carbon monoxide, atomic oxygen, $\beta$-cristobalite, ReaxFF force field, density functional theory calculations

Figures: 9

*Corresponding author: r.sayos@ub.edu

Version: 15 January 2014 


\section{Introduction}

Silica-based materials are important since they are commonly used in thermal protection systems (TPS) (e.g., in Space Shuttle tiles). Forthcoming development of reusable launch vehicles (RLV) is a prerequisite for guaranteeing long-term cheap access to space. In order to fulfil RLV objectives, new materials are required that allow the reduction of launch mass, improved modelling of aerothermodynamic phenomena, increased performance and reliability of propulsion systems, as well as innovative TPS. In this context, the mastering of the detailed chemical physics phenomena associated with TPS catalysis is therefore a key element. Consequently, theoretical, numerical and experimental developments are necessary in order to model more accurately the corresponding gassurface interactions. Currently, silica-based materials (e.g., reaction-cured glass (RCG) with 94\% of $\mathrm{SiO}_{2}, 4 \%$ of $\mathrm{B}_{2} \mathrm{O}_{3}$ and $2 \%$ of $\mathrm{SiB}_{4}$ ) are primarily used in some TPS surfaces. Among the different forms of $\mathrm{SiO}_{2}$ to be studied, either amorphous or crystalline (e.g., quartz, tridymite, cristobalite, etc.), the $\beta$-cristobalite is the most stable polymorph at high temperatures up to the melting point of 1996 $\pm 5 \mathrm{~K}$, which is below the high temperatures achieved during typical atmospheric entries. Moreover, $\beta$-cristobalite is the crystalline phase of silica with properties closest to those of amorphous silica (e.g., density, refractive index, band structure, etc.). Therefore, the study heterogeneous processes on this material can be very useful in this context.

On the other hand, Mars atmosphere is about $95 \%$ carbon dioxide, $3 \%$ nitrogen, $1.6 \%$ argon and traces of free oxygen, carbon monoxide, water and methane among other gases [1]. During the entry of space vehicles into planetary atmospheres hypersonic speeds are reached. At these conditions some of the main present gas species (i.e., $\mathrm{CO}_{2} / \mathrm{CO} / \mathrm{O}$ ) collide with the spacecraft surface [2] at high collision energies (i.e., about $4.5 \pm 1.0 \mathrm{eV}$ ) producing mainly the breaking of $\mathrm{CO}_{2}$ molecules into $\mathrm{CO}$ $+\mathrm{O}$. Thus, the main species present in the shock layer are $\mathrm{CO}$ and $\mathrm{O}$, which are able to contribute to several heterogeneous reactions (i.e., atomic and molecular adsorption, atomic recombination, atommolecule reactions,...) [3]. The resulting $\mathrm{O}$ atoms can be strongly adsorbed over the silica surface as 
confirmed by previous theoretical studies $[4,5,6,7]$ with an average adsorption energy of $5.9 \mathrm{eV}$ on top silicon position. Thus, the most probable scenario implies incoming $\mathrm{CO}$ molecules reacting over an O-preadsorbed silica surface to produce reflection, adsorption and $\mathrm{CO}_{2}$ formation, probably via an Eley-Rideal (ER) recombination mechanism that should be more likely than a LangmuirHinshelwood mechanism (LH).

Very scarce theoretical and experimental data are available about $\mathrm{CO}+\mathrm{O} / \mathrm{SiO}_{2}$ system. Thus, experimental investigation with carbon monoxide and oxygen mixtures on quartz indicate that oxygen recombination should be more important than $\mathrm{CO}$ oxidation in the range of pressures and temperatures studied [8]. The same conclusion was derived from measurements and simulations of the heat transfer produced to silica-based surfaces in dissociated carbon dioxide flows [3]. On the other hand, there are abundant studies on $\mathrm{CO}+\mathrm{O}$ over metals (e.g., $\mathrm{Au}$ [9], $\mathrm{Rh}[10])$ or other oxide surfaces (e.g., $\mathrm{TiO}_{2}[11]$ ), especially for the $\mathrm{LH}$ mechanism, which seems less important that ER one for silica surfaces.

In some previous studies we have extensively studied the atomic recombination of oxygen over $\beta$ cristobalite $[6,12]$. In the present work we want to ascertain the importance of the $\mathrm{CO}+\mathrm{O}$ reaction in comparison with the $\mathrm{O}+\mathrm{O}$ reaction to shed light on the mentioned experimental data. Thus, we present a quasiclassical trajectory (QCT) dynamics study of the title system using a reactive force field as a full dimensional potential energy surface (PES), once checked by means of new Density Functional Theory (DFT) calculations including long-range interactions along with experimental data.

This paper is organized as follows: Section 2 provides a brief description about the theoretical methods: DFT, Reactive force field and QCT; Section 3 describes the system model used and the tests carried out to compare DFT with the force field calculations, and Section 4 presents the main dynamical results and discussion. Finally, Section 5 gives the summary and conclusions. 


\section{Theoretical methods}

\section{A. DFT calculations}

Periodic DFT calculations have been performed using the Vienna ab initio simulation package (VASP) $[13,14,15,16]$. The calculations are based on the generalized gradient approximation (GGA) with the Perdew-Burke-Ernzerhof functional (PBE) [17]. The projector-augmented wave (PAW) technique within the frozen core approximation has been used to describe the electron-core interaction $[18,19]$. An energy cut-off of $550 \mathrm{eV}$ has been used in the plane-wave expansion and the Brillouin zone was integrated by using an $(3 \times 3 \times 1) k$-point mesh by means of the Monkhorst-Pack method [20]. All the slab calculations were performed on an $(1 \times 1)$ unit cell of $\beta$-cristobalite (i.e., $7.269 \times 7.269 \AA$ ) with a vacuum of $15 \AA$, large enough to prevent significant interactions between periodic images. The energy convergence in the electronic self-consistent procedure was maintained below $10^{-6} \mathrm{eV}$ for all geometrical calculations. Due to the important role that spin plays in atomic oxygen description, all calculations were spin-polarized. In addition, since the ReaxFF force field was fit at any geometry to the lower energy state, both spin states for $\mathrm{O}$ adsorption over different $\beta$ cristobalite sites have been calculated.

A 6-layer slab model (Si-O-Si-O-Si-O) was used for DFT calculations. To avoid any possible dipole field effects on the top surface due to the finite thickness of the slab, the dangling bonds at the bottom surface of the slab were passivated with hydrogen at their optimized positions. In earlier studies we checked the validity of this approach [4].

Since conventional DFT functionals are unable to describe correctly van der Waals interactions resulting from dynamical correlations between fluctuating charge distributions, long-range dispersion corrections have been taken into account within a DFT PBE-D2 approach of Grimme [21], as implemented in the VASP 5.2 version. The dispersion coefficients $\mathrm{C}_{6}$ used in the empirical force field of Grimme are listed in his own original paper [21] and the global scaling factor $\left(\mathrm{s}_{6}\right)$ has been set to 
0.75 because the PBE functional was chosen.

\section{B. ReaxFF Reactive Force Field}

The ReaxFF Reactive Force Field is a general bond-order based potential force field that uses a relationship between bond distance and bond order and also between bond-order and bond energy to be able to describe accurately the formation and rupture of bonds [22]. Non-bonded interactions (van der Waals, Coulomb,..) are calculated between every atom pair, irrespective of its connectivity. Excessive close-range non-bonded interactions are circumvented by including shielding terms. All connectivity-dependent interactions (i.e., valence and torsion angles) are made bond-order dependent to ensure that their energy contributions disappear upon bond dissociation. The ReaxFF uses a geometry-dependent charge calculation scheme to account for polarization effects during the course of the simulation.

The ReaxFF has been parameterized and tested for a great variety of processes: chemical reactions on solid surfaces (e.g., dissociation of water on titania [23, 24], hyperthermal oxidation of $\operatorname{Si}(100)$ by $\mathrm{O}$ and $\left.\mathrm{O}_{2}[25,26,27,28], ..\right)$, gas-phase reactions (e.g., n-heptane pyrolysis [29], oxidation of toluene [30],..), aqueous reactions (e.g., aqueous chloride and cooper chloride/water systems [31],..), reactions in zeolites (e.g., methanol to olefin reactions [32], confined reactive water in minerals $[33], .$.$) , etc. In particular, there are studies about the oxidation of silica by \mathrm{O}$ and $\mathrm{O}_{2}[7,34,35]$ and oxidation of silicon carbide by $\mathrm{O}_{2}$ and $\mathrm{H}_{2} \mathrm{O}[36,37]$, which are very related with the present work (i.e., $\mathrm{CO} / \mathrm{O} / \mathrm{SiO}_{2}$ system).

Usually, several sets of parameters have been obtained by fitting ab initio data (e.g., typically reaction energies, equilibrium geometries, heats of formation, bulk properties,..) for numerous systems (more than 5000 chemical species). The present parameter set was derived for SiC oxidation combining previous parameters for hydrocarbon oxidation and silicon/silicon oxide systems [36]. They predict for instance good values for the heat of formation and other properties of $\alpha-$ quartz, $\mathrm{CO}$ 
and $\mathrm{CO}_{2}$ compared with the experimental data.

Molecular dynamics simulation of chemical reactions via force fields is nowadays an usual approach to study chemical reactions of an extensive class of materials due to the great development of new reactive force fields [38], as for example the ReaxFF one. Moreover, these force fields allow as well the dynamics study of single elementary reactions (e.g., $\left.\mathrm{O}\left({ }^{3} \mathrm{P}\right)+\mathrm{SO}_{2}[39]\right)$, being the force field a powerful alternative to the traditional use of ab initio-based analytical or interpolated PES [40], with the necessary reduction of dimensionality of the system, as occurs frequently in gas-surface dynamics studies which assume often a rigid solid surface model. Thus, this is also the PES approach followed in the present work.

\section{QCT calculations}

A dynamical study involving the interaction of $\mathrm{CO}$ molecules with O-preadsorbed over $\beta$ cristobalite (001) surface was performed by means of the QCT method [41, 42, 43]. Several initial conditions were sampled in order to investigate several initial state-specific conditions. These calculations were carried out for fixed initial collision energies in the range of $0.05 \mathrm{eV} \leq \mathrm{E}_{\mathrm{col}} \leq 2.5 \mathrm{eV}$ (some extra calculations also at $4.0 \mathrm{eV}$ ) at two selected surface temperature $\mathrm{T}_{\text {surf }}=300$ and $900 \mathrm{~K}$ and several rovibrational states $(\mathrm{v}=0-5$ and $\mathrm{j}=0,20,35)$. The incoming incident velocity angle $\left(\theta_{\mathrm{v}}\right.$ in Fig. 1), which is defined with respect to the negative $z$ axis (i.e., $0^{\circ}$ for normal incidence), was fixed and its projection onto the $x-y$ plane (i.e., the azimuthal $\phi_{v}$ angle) was uniformly sampled within the $0^{\circ}-360^{\circ}$ interval. $\theta_{\mathrm{v}}$ was fixed at $0^{\circ}$ because normal incidence is a good approximation for the real conditions of spacecraft atmospheric entries. Nevertheless, some calculations were also run at $45^{\circ}$ in order to study the effect of the incoming incident velocity angle.

Initial molecular orientation angles $(\theta, \phi$ in Fig. 1) were sampled by the standard Monte Carlo method within the intervals $0^{\circ} \leq \theta \leq 180^{\circ}$ and $0^{\circ} \leq \phi \leq 360^{\circ}$, respectively. The initial $\mathrm{r}$ internuclear 
distance was sampled between the corresponding inner $\left(\mathrm{r}_{-}\right)$and outer $\left(\mathrm{r}_{+}\right)$turning points of each $\mathrm{CO}$ $(\mathrm{v}, \mathrm{j})$ rovibrational state. Initial position $\left(\mathrm{x}_{\mathrm{cm}}, \mathrm{y}_{\mathrm{cm}}\right)$ of the molecular centre of mass was randomly selected inside the $(1 \times 1)$ unit cell while $\mathrm{z}_{\mathrm{cm}}$ was set to $8.0 \AA$, where the interaction with surface is negligible.

The slab temperature $\left(\mathrm{T}_{\mathrm{S}}\right)$ was controlled by means of a Generalized Langevin equation (GLE) approach $[41,44]$ using the same procedure and friction coefficients (i.e., $\gamma_{\mathrm{g}, \mathrm{x}}=\gamma_{\mathrm{g}, \mathrm{y}}=\gamma_{\mathrm{g}, \mathrm{z}}=1.0 \times 10^{-4}$ $\mathrm{au}$ ) that were applied previously for the studies of atomic oxygen impinging on clean [45] and Opreadsorbed [12] $\beta$-cristobalite surfaces.

The QCTSURF [46] code developed in our group was used to calculate the trajectories integrating the Hamilton equations of the system using a Beeman algorithm. The time step used was $1 \times 10^{-16} \mathrm{~s}$, which ensures a total energy conservation along the trajectories lower than $1.0 \times 10^{-4} \mathrm{eV}$ in absence of the thermal bath. The total energy is not constant due to the thermal bath dissipation effect. Total integration time was set to a maximum value of $6.5 \mathrm{ps}$ (although it was set to $3.0 \mathrm{ps}$ for $\mathrm{E}_{\mathrm{col}} \geq 0.5 \mathrm{eV}$ ). These collision times allowed a correct classification of the trajectories among the different channels:

$$
\mathrm{CO}_{(\mathrm{g})}+\mathrm{O}^{\prime}-\beta-\text { cristobalite }_{(\mathrm{s})} \rightarrow \begin{cases}\mathrm{CO}_{(\mathrm{g})}+\mathrm{O}_{(\mathrm{ad})}^{\prime} & \text { (CO reflection) } \\ \mathrm{CO}_{(\mathrm{ad})}+\mathrm{O}_{(\mathrm{ad})}^{\prime} & \text { (CO adsorption) } \\ \mathrm{CO}_{(\mathrm{g} / \mathrm{ad})}+\mathrm{O}_{(\mathrm{ad} / \mathrm{g})} & \text { (O exchange) } \\ \mathrm{CO}_{2(\mathrm{~g})} & (\text { ER reaction) } \\ \mathrm{CO}_{2(\mathrm{ad})} & \left(C O_{2(a d)}\right. \text { formation) }\end{cases}
$$

The molecular adsorption classification was set for $Z_{\mathrm{cm}}$ values lower than $2.5 \AA$ and for a large number of total molecular rebounds on the surface (i.e., 8), as was also set previously for atomic oxygen impinging a clean or an O-preadsorbed graphite surface $[12,45]$. Moreover, if the molecule $\mathrm{z}_{\mathrm{cm}}$ was underneath the outermost layer surface the trajectory was initially classified as absorption (i.e., penetration into the slab) although in the results presented in the next section, absorption and adsorption probabilities were summed together, joining the same adsorption/absorption (sticking) process. On the other hand, $\mathrm{CO}$ was considered reflected if its $\mathrm{Z}_{\mathrm{cm}}$ was higher than $5.0 \AA$ with the 
direction of its velocity vector pointing to the vacuum. New formed $\mathrm{CO}_{2}$ molecules, that were kept adsorbed at the end of the trajectory, were classified as $\mathrm{CO}_{2(\mathrm{ad})}$ formation, hence not included as ER reaction, which produces only $\mathrm{CO}_{2}$ gas molecules.

The number of total trajectories $\left(\mathrm{N}_{\mathrm{T}}\right)$ calculated for each state-specific condition (i.e., $\mathrm{v}, \mathrm{j}, \mathrm{E}_{\mathrm{col}}$, $\mathrm{T}_{\text {surf }}$ and $\theta_{\mathrm{v}}$ ) was about 3000 for $\mathrm{E}_{\mathrm{col}} \geq 0.5 \mathrm{eV}$ and 6000 for $\mathrm{E}_{\mathrm{col}}<0.5 \mathrm{eV}$. These batches of trajectories ensure a standard deviation lower than $4 \%$ in the channel probabilities for the most probable processes (i.e., atomic reflection and adsorption).

\section{System and PES model}

The system model used in this dynamical study is a $(3 \times 3 \times 1)$ supercell of $\beta$-cristobalite (i.e., $21.04 \times 21.04 \AA$ ) composed by 234 atoms ( $89 \mathrm{Si}$ atoms and $145 \mathrm{O}$ atoms) arranged in 9 layers starting and finishing with Si ones. The slab geometry of this supercell corresponds to the ReaxFF fully relaxed value. It is important to note that ReaxFF allows working with periodic conditions but the computer QCTSURF [46] code is not prepared for this, so some restrictions have been added to the surface model in order to do the computational treatment. Thus, only the central area that corresponds to an $(1 \times 1)$ unit cell was sampled during the $\mathrm{CO}$ molecular collisions, with the preadsorbed oxygen atom initially located at its central top Si. Moreover, in order to avoid any reconstruction and amorphization of the slab as the study over the well defined (001) face was intended, only a few atoms of the central cell were allowed to move, being the surrounding cells kept rigid. Particularly, four atoms ( $2 \mathrm{Si}$ and $2 \mathrm{O}$ atoms), those just below the $\mathrm{O}$ adatom were free for movement. This degree of slab movement allowed the $\mathrm{O}$ adatom to oscillate around the initial position and to permit a reliable exchange of energy with the slab and surface temperature inclusion.

The total PES was based on ReaxFF reactive force field for the global system (i.e., $2 \mathrm{O}$ and $1 \mathrm{C}$ atoms plus 234 slab atoms). Some additional tests were carried out to check the reliability of the 
selected ReaxFF parameter set. A first check can be carried out comparing several properties of the molecules and of the solid against experimental and DFT PBE-D2 data (Table 1). For the case of the single molecules as $\mathrm{CO}, \mathrm{O}_{2}$ and $\mathrm{CO}_{2}$, the agreement respect the experimental dissociation energies [47] is good and better for ReaxFF than for DFT PBE-D2, although respect the equilibrium distances is very similar. Another important point regards the description of silica polymorphs (e.g., $\beta$ cristobalite and $\alpha$-quartz). The ReaxFF optimal lattice parameters along with its cohesive energy are in excellent agreement with experimental data $[47,48]$ for both polymorphs shown in Table 1 , even better than the DFT PBE-D2 data. The calculated formation enthalpies, using the formula $\Delta_{\mathrm{f}} \mathrm{H}^{\mathrm{SiO}_{2(\mathrm{~s})}}=\mathrm{E}_{\text {bulk }}^{\mathrm{SiO}_{2(\mathrm{~s})}}-\left[\mathrm{E}_{\text {bulk }}^{\mathrm{Si}(\mathrm{s})}+\mathrm{E}_{\mathrm{gas}}^{\mathrm{O}_{2}}\right]$, were -9.29 eV and -9.31 eV for $\beta$-cristobalite and $\alpha$-quartz, respectively; these values compare quite well with the experimental data $(-9.38 \mathrm{eV}$ (at $298.15 \mathrm{~K})$ and $-9.39 \mathrm{eV}($ at $0 \mathrm{~K})$ or $-9.44 \mathrm{eV}$ (at $298.15 \mathrm{~K})$, respectively [47]).

We have also studied the adsorption of $\mathrm{O}, \mathrm{CO}$ and $\mathrm{CO}_{2}$ on the main sites $[4,45]$ over the Si-ended $(1 \times 1) \beta$-cristobalite $(001)$ surface: on top Si $(\mathrm{T} 1)$, a hollow $(\mathrm{H} 1)$ and a bridge between two Si atoms (B1). We have kept frozen the slab geometry at its equilibrium value to simplify DFT calculations because previous studies [4] indicate that the effect of the slab relaxation is small.

Each species prefers a different site position. Thus, the oxygen atoms prefer on top sites (Fig. 2a), the $\mathrm{CO}$ molecule the $\mathrm{B} 1$ sites (Fig. 2b) and the $\mathrm{CO}_{2}$ molecule the $\mathrm{H} 1$ sites (Fig. 2c). The agreement between DFT PBE-D2 and ReaxFF curves is almost perfect for the strong O adsorption over T1 site (Fig. 2a) leading to large adsorption energies of -5.85 and $-5.80 \mathrm{eV}$, respectively (negative values mean favourable adsorption). It is worth noting the good response of this force field in reproducing the $\mathrm{O}$ atom far from the surface (triplet state) and also when it is well adsorbed (singlet state). Present spin-polarized DFT PBE-D2 calculations have corroborated this fact in agreement with earlier studies [4]. Thus, both spin states can be distinguishable only by using this technique. For the case of $\mathrm{CO}$ molecule adsorption different approaches of the molecule (i.e., perpendicular by $\mathrm{C}$ or $\mathrm{O}$ end and 
parallel configurations) over B1 site are compared (Figs. 2b(i-iv). The agreement between ReaxFF and DFT PBE-D2 method is good mainly for the approach of CO molecule perpendicular to the surface by the $\mathrm{C}$ side, Fig. 2b(i), (cf. adsorption energies of -0.14 and $-0.15 \mathrm{eV}$ for ReaxFF and DFT PBE-D2, respectively) although force field adsorption occurs at higher distances from the surface. Thus, the minimum energy approach predicted by DFT PBE-D2 is $1.96 \AA$ whereas ReaxFF predicts it to be $2.76 \AA$. The approach by the O side (Fig. $2 \mathrm{~b}(\mathrm{iii})$ ) is overestimated by ReaxFF. Thus, for the most stable vdW complex the adsorption energy corresponds to $-0.34 \mathrm{eV}$ at a distance of $2.32 \AA$ from the surface for ReaxFF while it corresponds to an adsorption energy of $-0.03 \mathrm{eV}$ at a distance of 2.74 $\AA$ for the case of DFT PBE-D2 method. For parallel approach (Figs. 2b(ii, iv)) ReaxFF also overestimates the adsorption (cf. adsorption energies of $-0.26 \mathrm{eV}$ at $2.09 \AA$ for ReaxFF and $-0.04 \mathrm{eV}$ at $3.00 \AA$ for the case of DFT PBE-D2 method). Previous theoretical studies on the CO adsorption over similar oxides as rutile show as well analogous adsorption energies (e.g., $-0.32 \mathrm{eV}$ for $\mathrm{TiO}_{2}(100)$ [49] or $\mathrm{TiO}_{2}(110)$ surfaces [50]). The adsorption over metals seems to be more stable (e.g., $-0.77 \mathrm{eV}$ over clean $\mathrm{Au}(321)[51])$.

Fig. 2c shows the most stable vdW complex for $\mathrm{CO}_{2}$ adsorption on $\mathrm{H} 1$ site, corresponding to a perpendicular configuration. ReaxFF also tends to overestimate the molecular adsorption (cf. adsorption energies of $-0.32 \mathrm{eV}$ at a distance from the surface of $2.68 \AA$ in the case of ReaxFF and $-0.15 \mathrm{eV}$ at a distance of $2.08 \AA$ in the case of DFT PBE-D2). Dispersion-corrected DFT calculations of $\mathrm{CO}_{2}$ adsorption on oxidized rutile (110) surfaces [52] show adsorption energies within the range 0.39-0.44 eV at low coverages for both parallel and almost perpendicular (tilted) configurations, in agreement with available experimental data. Adsorption on siliceous zeolites, more similar to the present $\beta$-cristobalite surface, presents lower adsorption energies (i.e., $-0.32 \mathrm{eV}$ at PBE-D2 level for $\mathrm{CO}_{2}$ in the centre of an eight-membered ring [53]), similar to present ReaxFF values.

In spite of the differences between ReaxFF and DFT PBE-D2 calculations for both molecular adsorptions, these are quite low and it is expected that the small $\mathrm{CO}$ or $\mathrm{CO}_{2}$ adsorption will have a 
very small effect on the dynamics study (see next section). For the $\mathrm{CO}$ case, this will enhance slightly the adsorption mainly at low collision energies and for the $\mathrm{CO}_{2}$ case, this can increase a bit the $\mathrm{CO}_{2}$ (ad) channel respect the $\mathrm{CO}_{2}$ gas one.

\section{QCT dynamical results}

Fig. 3 shows the observed reactions probabilities for the different heterogeneous processes as a function of the collision energy, fixing the initial rovibrational $\mathrm{CO}$ state (i.e., $v=2, j=0$ ), the surface temperature $\left(\mathrm{T}_{\text {surf }}=300 \mathrm{~K}\right)$ and the angle of incidence $\left(\theta_{\mathrm{v}}=0^{\circ}\right)$. CO reflection is the main channel, being $\mathrm{CO}$ adsorption the second one (Fig. 3a). This latter becomes more important at low collision energies as could be expected due to the low $\mathrm{CO}$ adsorption energies, predicted by both ReaxFF or DFT PBE-D2 methods. Other minor processes observed were: the $\mathrm{O}$ exchange between $\mathrm{CO}$ and $\mathrm{O}$ adatom and the $\mathrm{CO}_{2}$ formation in gas phase (i.e., ER reaction) or producing adsorbed $\mathrm{CO}_{2}$. The increase of $\mathrm{E}_{\mathrm{col}}$ diminishes the $\mathrm{CO}_{2}$ adsorption hence increasing even more the ER reaction. Logically, the integration at longer collision times of trajectories classified as $\mathrm{CO}_{2(\mathrm{ad})}$ could favour slightly the ER probability. Since the preadsorbed $\mathrm{O}$ atom remains strongly linked to the silica surface (Fig. 2a), the possibility of extracting this adatom from the surface with an incoming atom or molecule should be in principle low. Moreover, the fact that the $\mathrm{CO}$ bond is very strong (Table 1) leads to a slightly endothermic process for the $\mathrm{CO}_{2}$ formation via an $\mathrm{ER}$ mechanism (i.e., $\Delta \mathrm{E}=0.17 \mathrm{eV}$ without inclusion of ZPE), which is coherent with the low calculated ER probabilities.

The $\mathrm{CO}$ vibrational excitation effect is presented in Fig. 4. This reduces the reflection of CO molecules and favours the non-dissociative $\mathrm{CO}$ adsorption (Fig. $4 \mathrm{a}$ and $4 \mathrm{~b}$ ) along with the other minor processes (Fig. 4c, $4 \mathrm{~d}$ and $4 \mathrm{e}$ ) within the interval $0 \leq \mathrm{v} \leq 2$.

At low collision energies, where the $\mathrm{CO}$ adsorption is important, the analysis of the final position of $\mathrm{CO}$ adsorbed molecules shows that at $\mathrm{E}_{\mathrm{col}}=0.05 \mathrm{eV}$ the molecule gets absorbed around the other 
available free T1 sites, mainly inside the unit cell but also outside. This effect is more evident as vibrational excitation increases from 0 to 2 . In the case of $\mathrm{E}_{\mathrm{col}}=0.3 \mathrm{eV}$ again the $\mathrm{CO}$ molecule prefers the adsorption on $\mathrm{T} 1$ sites principally when it approaches by the $\mathrm{C}$ end; when the approach is by the $\mathrm{O}$ atom it prefers to get adsorbed around the $\mathrm{B} 1$ sites close to the central $\mathrm{T} 1$ site, where the preadsorbed oxygen atom is located.

Vibrational excitation and $\mathrm{E}_{\mathrm{col}}$ rise enhance ER reaction (Fig. 4d). There is a high-energy threshold (e.g., $0.5 \mathrm{eV}$ for $\mathrm{v}=0$ ), which is significantly reduced when $\mathrm{v}$ is augmented. However, for $\mathrm{v}>2$ the ER probabilities are lower. The same decrease in probabilities is observed for $\mathrm{O}$ exchange, $\mathrm{CO}_{2}$ (ad) formation and $\mathrm{CO}$ adsorption processes, producing thus an increase of $\mathrm{CO}$ reflection. The high vibrational amplitude worsens the possibility of $\mathrm{CO}$ molecule to reach the $\mathrm{B} 1 / \mathrm{H} 1$ open areas of solid surface, where simultaneously interacts with the preadsorbed $\mathrm{O}$ atom. In this case, extended $\mathrm{CO}$ molecule interacts more repulsively with silicon atoms belonging to the unit cell and becomes mostly reflected.

Regarding the formation of $\mathrm{CO}_{2 \text { (ad) }}$ (Fig. 4c), it is observed a clear shift of the maximum in the reaction probability for higher initial CO vibrational levels, possibly by the same repulsive interaction mentioned before, which implies that the molecular desorption can begin at lower collision energies.

The rotational $\mathrm{CO}$ excitation effect is almost negligible for reflection or adsorption processes. Only for minor processes (Fig. 5) there is any noticeable effect. For instance, $\mathrm{CO}_{2}$ (g or ad) formation is slightly diminished because the $\mathrm{C}$ end of $\mathrm{CO}$ is deviated from $\mathrm{O}_{\mathrm{ad}}$, while exchange of $\mathrm{O}$ atom is somewhat favoured.

The surface temperature effect, introduced through the thermal bath, is very small as can be inferred comparing reaction probabilities at $\mathrm{T}_{\text {surf }}=300 \mathrm{~K}$ and $900 \mathrm{~K}$ (Figs. 3 and 6, respectively). Only a slight decrease in the $\mathrm{CO}_{2(\mathrm{ad})}$ reaction probabilities for high surface temperatures is appreciated at $\mathrm{CO}(\mathrm{v}=2)$ as usual due to the expected increase in the molecular desorption. This behaviour was similarly observed for $\mathrm{O}$ or $\mathrm{O}_{2}$ colliding over clean or O-preadsorbed $\beta$-cristobalite surfaces [12, 45, 
54].

The effect of the incident angle on the reactivity can be seen in Fig. 7. CO reflection becomes the most important process, especially at higher collision energies, being all other processes highly reduced. This change in reactivity comes out since the perpendicular component of the collision energy is halved in off-normal incidence $\left(\theta_{\mathrm{v}}=45^{\circ}\right)$, which implies lower reaction probabilities according with the behaviour shown in Fig. 3. In the case of $\mathrm{CO}$ adsorption, the reaction probabilities are very similar although a bit larger for normal incidence and very low collision energies because ReaxFF shows larger adsorption energies for non-parallel configurations (i.e., $-0.34 \mathrm{eV}$ for perpendicular approach and -0.26 for parallel approach, Fig. 2b), which are less favoured for offnormal incidence.

The present results confirm that $\mathrm{CO}_{2}$ formation ( $\mathrm{g}$ or ad) from $\mathrm{CO}+\mathrm{O}_{\mathrm{ad}}$ should be less important than $\mathrm{O}_{2}$ formation from $\mathrm{O}+\mathrm{O}_{\mathrm{ad}}$ over silica [12] for similar initial conditions (i.e., collision energy, incident angle,...) in agreement with experimental data $[3,8]$. However, there are two facts that can change this situation: the increase of either the collision energy or the CO vibrational excitation. Thus, at hyperthermal conditions $\mathrm{CO}+\mathrm{O}_{\mathrm{ad}}$ reaction could become more important that it was assumed in previous works.

Particular attention has been devoted to the analysis of CO reflected molecules in order to know the different mechanisms of losing and gaining energy of $\mathrm{CO}$ with the solid surface. Fig. 8 shows the final vibrational distributions of reflected $\mathrm{CO}$ molecules $\left(\mathrm{P}\left(\mathrm{v}^{\prime}\right)\right)$ for several initial conditions (i.e., $\mathrm{E}_{\mathrm{col}}$ and $\mathrm{v}$ ), fixing $\theta_{\mathrm{v}}=0^{\circ}, \mathrm{T}_{\text {surf }}=300 \mathrm{~K}$ and $\mathrm{CO}$ at $(\mathrm{j}=0)$. The peaks of the different distributions and the average of the final vibrational number $\left(\left\langle v^{\prime}>\right)\right.$ confirm a large increase of the vibrational excitation after the collision on the surface, being the number of molecules that reduce its vibration very low. The initial $\mathrm{CO}$ vibrational excitation affects the shape of the final $\mathrm{P}\left(\mathrm{v}^{\prime}\right)$ distributions. When $\mathrm{CO}$ molecule is initially at $\mathrm{v}=2$ the final peak is also maintained at $\mathrm{v}^{\prime}=2$. The shape of $\mathrm{P}\left(\mathrm{v}^{\prime}\right)$ depends little on the initial amount of collision energy although the peak intensity gets lower as $\mathrm{E}_{\text {col }}$ increase. At $\mathrm{v}$ 
$=2$, a bimodal distribution tends to appear at low collision energies (i.e., middle panels in Fig. 8), being even more evident at $v=4$ (i.e., right panels in Fig. 8). Thus, two microscopic mechanisms could be inferred: molecules that gain or lose vibrational energy. The analysis of 100 trajectories in both peaks shows that $\mathrm{CO}$ molecules that interact with atoms belonging to the non-rigid slab (i.e., central cell) account for the peak at lower v' values whereas those trajectories impinging on the rigid slab (i.e., surrounding cells) are finally scattered with higher vibrational energy, thus contributing to the peak at higher v' values in the vibrational distribution.

In particular, an analysis of the contribution of both kind of trajectories (i.e., non-rigid vs. rigid collisions) for the colder peak (i.e., $v^{\prime}=3$ ) for $v=4$ and $E_{\mathrm{col}}=0.50 \mathrm{eV}$ showed values of $53 \%$ and 47 $\%$, respectively, while for the hotter peak $\left(\mathrm{v}^{\prime}=9\right)$ were $25 \%$ and $75 \%$, respectively. Therefore, in case of using a larger non-rigid unit cell the final distributions would be expected to be only centred at the lower v' peak.

The analysis of rotational distributions for the most populated final vibrational level (not shown here) has been also carried out and shows typical one-peaked distributions. As usual, the increase in $\mathrm{E}_{\mathrm{col}}$ drives to wider distributions peaked at larger $\mathrm{j}$ ' values. The average $<\mathrm{j}$ ' $>$ values increase with both the initial collision energy and the vibrational initial state (e.g., for $\mathrm{v}=2$ and $\mathrm{E}_{\mathrm{col}}=0.50 \mathrm{eV}$ and $2.50 \mathrm{eV},\left\langle\mathrm{j}^{\prime}>=17.7\right.$ and 37.8 respectively for $\mathrm{v}^{\prime}=2$ ). Moreover, for $\mathrm{v}=4$, an additional analysis of the rotational distributions corresponding to the hottest v' peak (i.e., v' $=9$ ) shows quite similar rotational distributions as those obtained for the lowest peak at $\mathrm{v}^{\prime}=3$.

Final rotational and vibrational distributions support that scattered molecules become internally excited (i.e., vibrationally and rotationally). This point can be also shown by plotting the increments of total and collisional molecular energies: $\Delta \mathrm{E}_{\mathrm{tot}}=\mathrm{E}_{\mathrm{tot}}{ }^{\prime}-\mathrm{E}_{\mathrm{tot}}$ and $\Delta \mathrm{E}_{\mathrm{col}}=\mathrm{E}_{\mathrm{col}}$ '- $\mathrm{E}_{\mathrm{col}}$ (primes are used for final values). Fig. 9 shows (i.e., see distribution shapes and average values) that reflected CO molecules are mainly scattered with lower final collision energies. However, the distributions of the final total energies tend to be hotter than the initial ones, being broader for larger initial collision 
energies. Thus, there is a clear augment of the molecular internal energy as it was stated previously, partially counterbalanced by a decrease in the collision energy, producing a general increase in the total molecular energy. This behaviour would imply that the inelastic collisions of CO over silica, which is the principal process, would not heat too much the solid surface. Hence, this material could be appropriate to be used in TPS materials for $\mathrm{CO}_{2}$ rich atmospheres, where $\mathrm{CO}$ and $\mathrm{O}$ species are important.

\section{Summary and conclusions}

A dynamical quasiclassical trajectory study have been carried out for the collision of $\mathrm{CO}(\mathrm{v}, \mathrm{j})$ molecules over an O-preadsorbed $\beta$-cristobalite surface by using a based ReaxFF force field potential energy surface. Additional DFT calculations and available experimental data support the reliability of the present set of ReaxFF parameters.

The main elementary processes observed were the molecular reflection and the non-dissociative molecular adsorption, the first one increasing and the second one decreasing when collision energy is augmented. Another minor elementary processes were: the $\mathrm{O}$ exchange between $\mathrm{CO}$ and $\mathrm{O}$ adatom and the $\mathrm{CO}_{2}$ formation in gas phase (i.e., ER reaction) or producing finally adsorbed $\mathrm{CO}_{2}$.

The Eley-Rideal reaction increases with collision energy and with the $\mathrm{CO}$ initial vibrational excitation. This latter also reduces the reflection of $\mathrm{CO}$ molecules and favours the non-dissociative $\mathrm{CO}$ adsorption along with the other minor processes within the interval $0 \leq \mathrm{v} \leq 2$.

The effects of rotational $\mathrm{CO}$ excitation and surface temperature are almost negligible for all processes. The effect of the incident angle is important, showing that for off-normal incidence the 
$\mathrm{CO}$ reflection becomes the most important process, especially at higher collision energies, being all other processes greatly reduced.

The present study confirms that $\mathrm{CO}_{2}$ formation ( $\mathrm{g}$ or ad) from $\mathrm{CO}+\mathrm{O}_{\mathrm{ad}}$ reaction should be less important than $\mathrm{O}_{2}$ formation from $\mathrm{O}+\mathrm{O}_{\text {ad }}$ reaction over silica for similar initial conditions (i.e., collision energy, incident angle,..) in agreement with experimental data.

The scattered $\mathrm{CO}$ molecules, which constitute the main elementary process, tend to be translationally colder and internally hotter (rotationally and vibrationally) than the initial ones. This implies that the inelastic collisions of CO over a silica surface almost do not heat this solid surface. This behaviour along with the low reactivity suggests that this material could be appropriate to be integrated in the composition of TPS materials to be used in dissociated $\mathrm{CO}_{2}$ atmospheres.

\section{Acknowledgements}

This work was supported in part by the Spanish Ministry of Science and Innovation (Project CTQ2009-07647), by the Autonomous Government of Catalonia (Project 2009SGR1041) and by the European Commission research funding (Project FP7-SPACE-2009-242311). We thank to Prof. van Duin for providing us with a ReaxFF standalone non-parallel fortran-77 code to be used together with our QCTSURF code. We also thank to Alejandro Díaz, who carried out some extra QCT calculations at the end of this study. 


\section{TABLES}

Table 1 Comparison of ReaxFF (top), DFT PBE-D2 (middle) and experimental (bottom) data for several molecules and polymorphs of silica ${ }^{a}$

\begin{tabular}{lcc}
\hline & $\operatorname{Re}(\AA)$ & $D_{e}(\mathrm{eV})$ \\
\hline $\mathrm{CO}\left(\mathrm{X}^{1} \Sigma^{+}\right)$ & 1.123 & 11.68 \\
& 1.144 & 11.53 \\
& 1.128 & 11.22 \\
& 1.249 & 5.82 \\
$\mathrm{CO}_{2}\left(\mathrm{X}^{1} \Sigma_{\mathrm{g}}{ }^{+}\right)$ & 1.177 & 6.30 \\
& 1.162 & 5.61 \\
$\mathrm{O}_{2}\left(\mathrm{X}^{3} \Sigma_{\mathrm{g}}{ }^{-}\right)$ & 1.265 & 5.21 \\
& 1.234 & 6.07 \\
& 1.208 & 5.23 \\
\hline
\end{tabular}

$\begin{array}{lcc} & 7.014,7.014 & 19.18 \\ \begin{array}{l}\text {-cristobalite } \\ \text { (cubic, P213) }\end{array} & 7.269,7.269 & - \\ & 7.147,7.147 & 19.21 \\ & & \\ & 4.892,5.379 & 19.20 \\ \begin{array}{l}\alpha \text {-quartz } \\ \text { (trigonal,P3221) }\end{array} & 4.801,5.323 & 19.45 \\ & 4.913,5.405 & 19.27\end{array}$

${ }^{a}$ Equilibrium distances and dissociation energies(without inclusion of ZPE) for molecules and lattice parameters and cohesive energies for bulk silica (ReaxFF, DFT PBE-D2 and experimental $[47,48])$. Experimental $\mathrm{E}_{\mathrm{coh}}$ derived from $\Delta_{\mathrm{f}} \mathrm{H}^{\mathrm{o}}$ at $25^{\circ} \mathrm{C}$ [47] for the process: $\mathrm{SiO}_{2}$ (solid) $\rightarrow$ $\mathrm{Si}($ g,ideal $)+2 \mathrm{O}(\mathrm{g}$, ideal $)$. 


\section{FIGURE CAPTIONS}

\section{Fig. 1}

Coordinates system for $\mathrm{CO}$ molecule interacting with an O-preadsorbed $\beta$-cristobalite (001) surface. The internal coordinates $(\mathrm{r}, \theta, \phi)$ define the molecular CO orientation, while $\left(\theta_{\mathrm{v}}, \phi_{\mathrm{v}}\right)$ define the angle of incoming centre of mass velocity vector $\left(\overrightarrow{\mathrm{v}}_{\mathrm{cm}}\right)$. The definitions of the $\mathrm{x}$ and $\mathrm{y}$ axes are not unique although it is unimportant since the whole range of $\phi_{\mathrm{v}}$ angles is considered (i.e., $0-360^{\circ}$ ).

\section{Fig. 2}

DFT PBE-D2 (dashed and dotted lines) and ReaxFF (solid line) energy curves for several species over clean $\beta$-cristobalite surface at its optimum geometry, whose is fixed: (a) O over T1 site, (b) CO over B1 site for two perpendicular $\left(\theta=0^{\circ}\right.$ (i), $180^{\circ}$ (iii) ; $\mathrm{C}$ or $\mathrm{O}$ sides $)$ and two parallel $\left(\theta=90^{\circ}, \phi=\right.$ $180^{\circ}$ (ii), $90^{\circ}$ (iv)) configurations, and (c) $\mathrm{CO}_{2}$ over $\mathrm{H} 1$ site for a perpendicular approach. Geometries of molecules are optimized at each point. The $\mathrm{z}$ origin is established at the first layer (Si) of the surface.

\section{Fig. 3}

QCT reaction probabilities for an O-precovered $\beta$-cristobalite surface as a function of CO collision energy, fixing initial $\theta_{\mathrm{v}}=0^{\circ}, \mathrm{T}_{\text {surf }}=300 \mathrm{~K}$ and $\mathrm{CO}$ at $(\mathrm{v}=2, \mathrm{j}=0)$.

\section{Fig. 4}

QCT reaction probabilities for an O-precovered $\beta$-cristobalite surface as a function of $\mathrm{CO}(\mathrm{v})$ vibrational levels and collision energies, fixing initial $\theta_{\mathrm{v}}=0^{\circ}, \mathrm{T}_{\text {surf }}=300 \mathrm{~K}$ and $\mathrm{CO}$ at $(\mathrm{j}=0)$. Note different Y-axis scales.

\section{Fig. 5}


QCT reaction probabilities for an O-precovered $\beta$-cristobalite surface as a function of CO $(\mathrm{j})$ rotational levels and collision energies, fixing initial $\theta_{\mathrm{v}}=0^{\circ}, \mathrm{T}_{\text {surf }}=300 \mathrm{~K}$ and $\mathrm{CO}$ at $(\mathrm{v}=0)$.

\section{Fig. 6}

QCT reaction probabilities for an O-precovered $\beta$-cristobalite surface as a function of CO collision energy, fixing initial $\theta_{\mathrm{v}}=0^{\circ}, \mathrm{T}_{\text {surf }}=900 \mathrm{~K}$ and $\mathrm{CO}$ at $(\mathrm{v}=2, \mathrm{j}=0)$.

\section{Fig. 7}

QCT reaction probabilities for an O-precovered $\beta$-cristobalite surface as a function of CO collision energy, fixing initial $\theta_{\mathrm{v}}=45^{\circ}, \mathrm{T}_{\text {surf }}=300 \mathrm{~K}$ and $\mathrm{CO}$ at $(\mathrm{v}=2, \mathrm{j}=0)$.

\section{Fig. 8}

QCT final vibrational distributions of reflected $\mathrm{CO}\left(\mathrm{v}^{\prime}\right)$ molecules for different initial $\mathrm{E}_{\mathrm{col}}$ values and $\mathrm{CO}$ vibrational levels, fixing $\theta_{\mathrm{v}}=0^{\circ}, \mathrm{T}_{\text {surf }}=300 \mathrm{~K}$ and $\mathrm{CO}$ at $(\mathrm{j}=0)$. The distributions shown are normalized to population unity. Average final vibrational values are also indicated.

\section{Fig. 9}

Differences between initial and final collision energies $\left(\Delta \mathrm{E}_{\mathrm{col}}\right.$, solid line $)$ and total energies $\left(\Delta \mathrm{E}_{\mathrm{tot}}\right.$, dashed line) of $\mathrm{CO}$ molecules, which are reflected on an O-precovered $\beta$-cristobalite surface, as a function of initial $\mathrm{CO}(\mathrm{v})$ vibrational levels and collision energies. Initial fixed conditions: $\mathrm{CO}(\mathrm{j}=0)$, $\theta_{\mathrm{v}}=0^{\circ}$ and $\mathrm{T}_{\text {surf }}=300 \mathrm{~K}$. Average values are indicated between parentheses.

\section{Fig. 1}




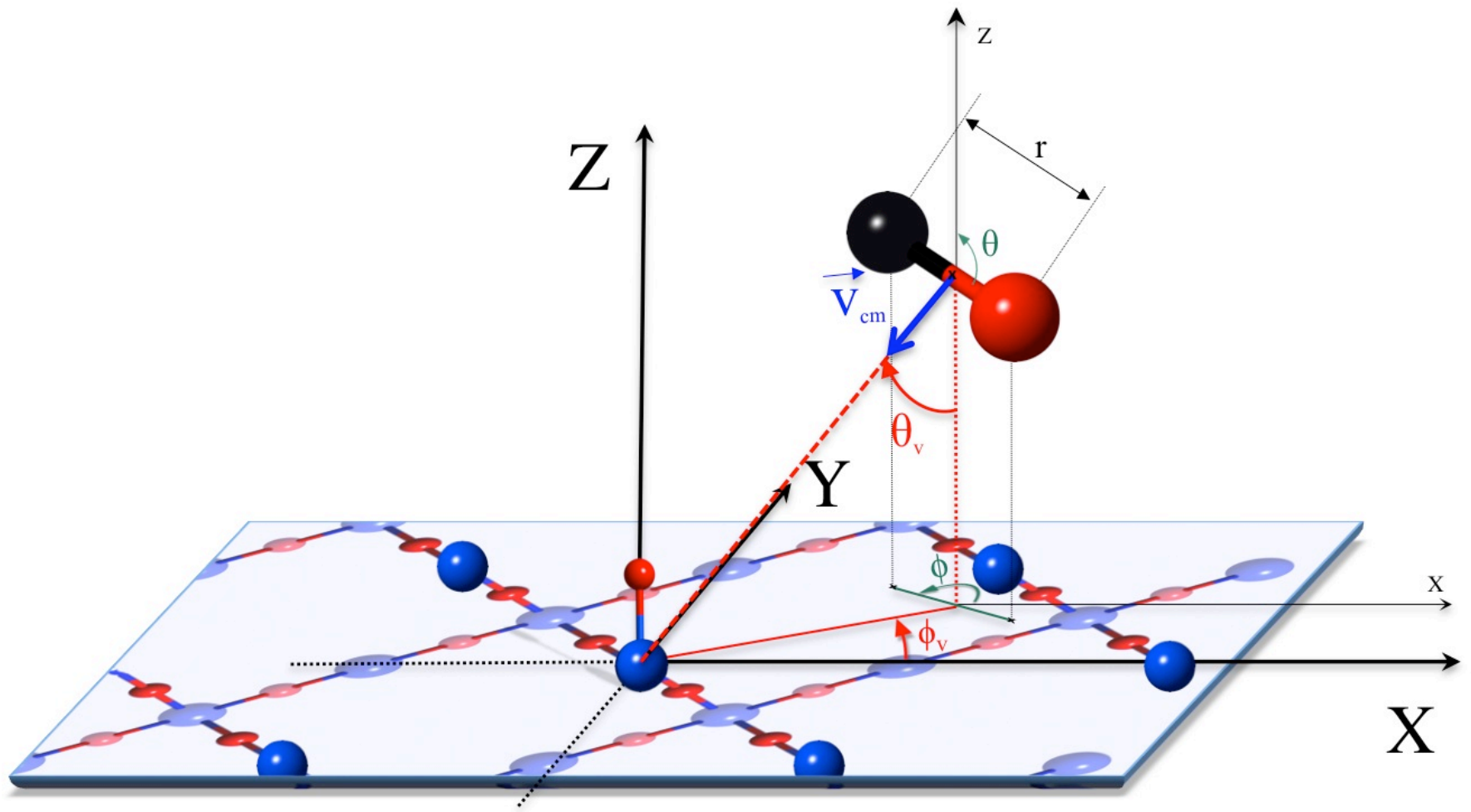


Fig. 2 

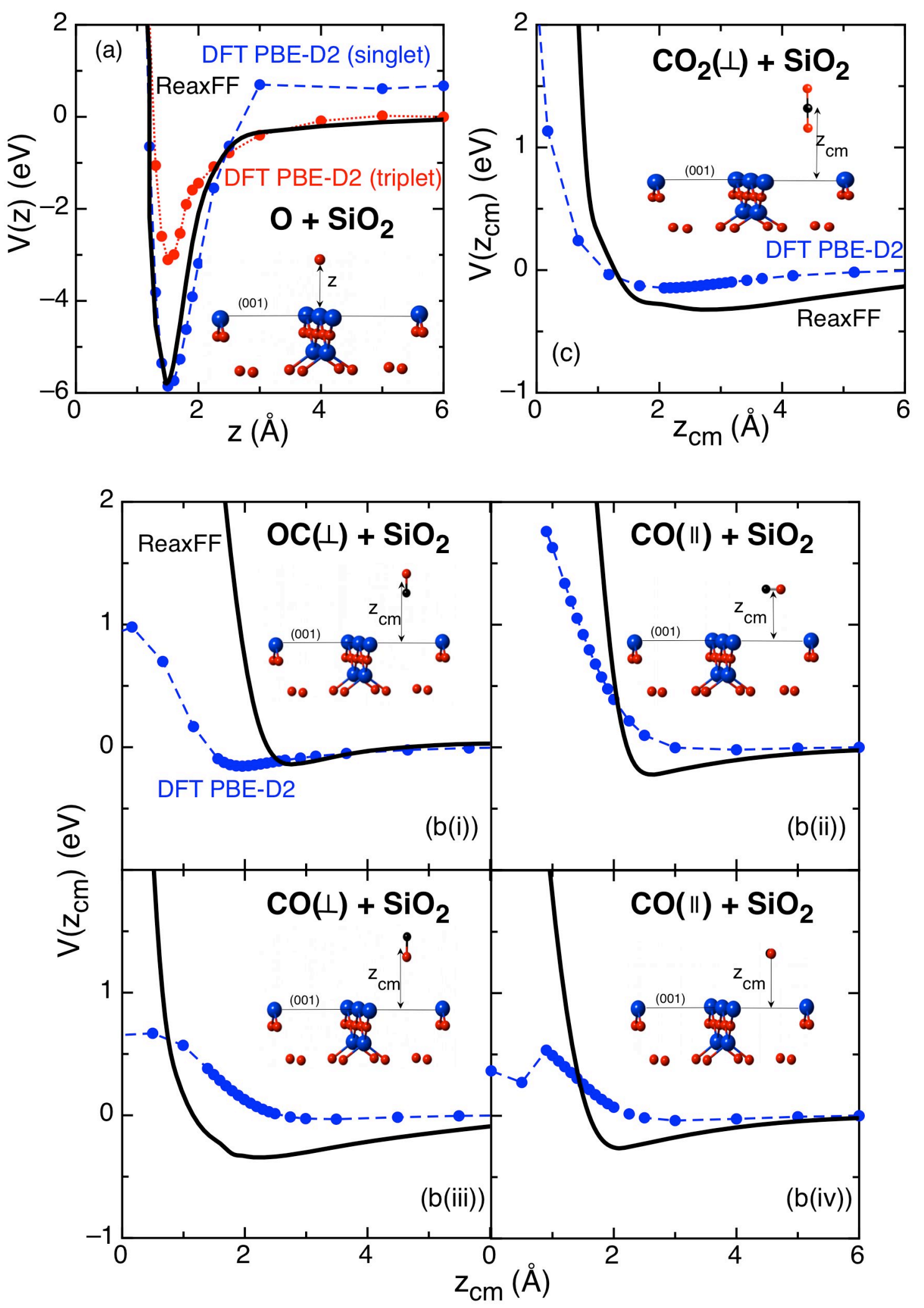

Fig. 3 


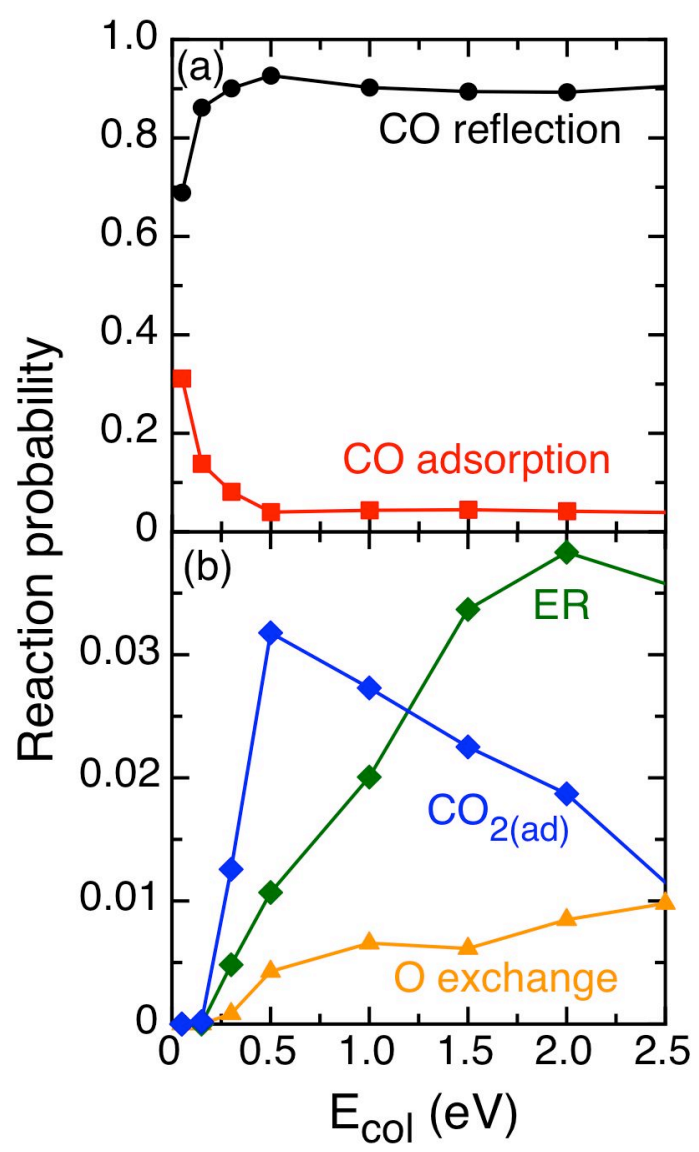


Fig. 4
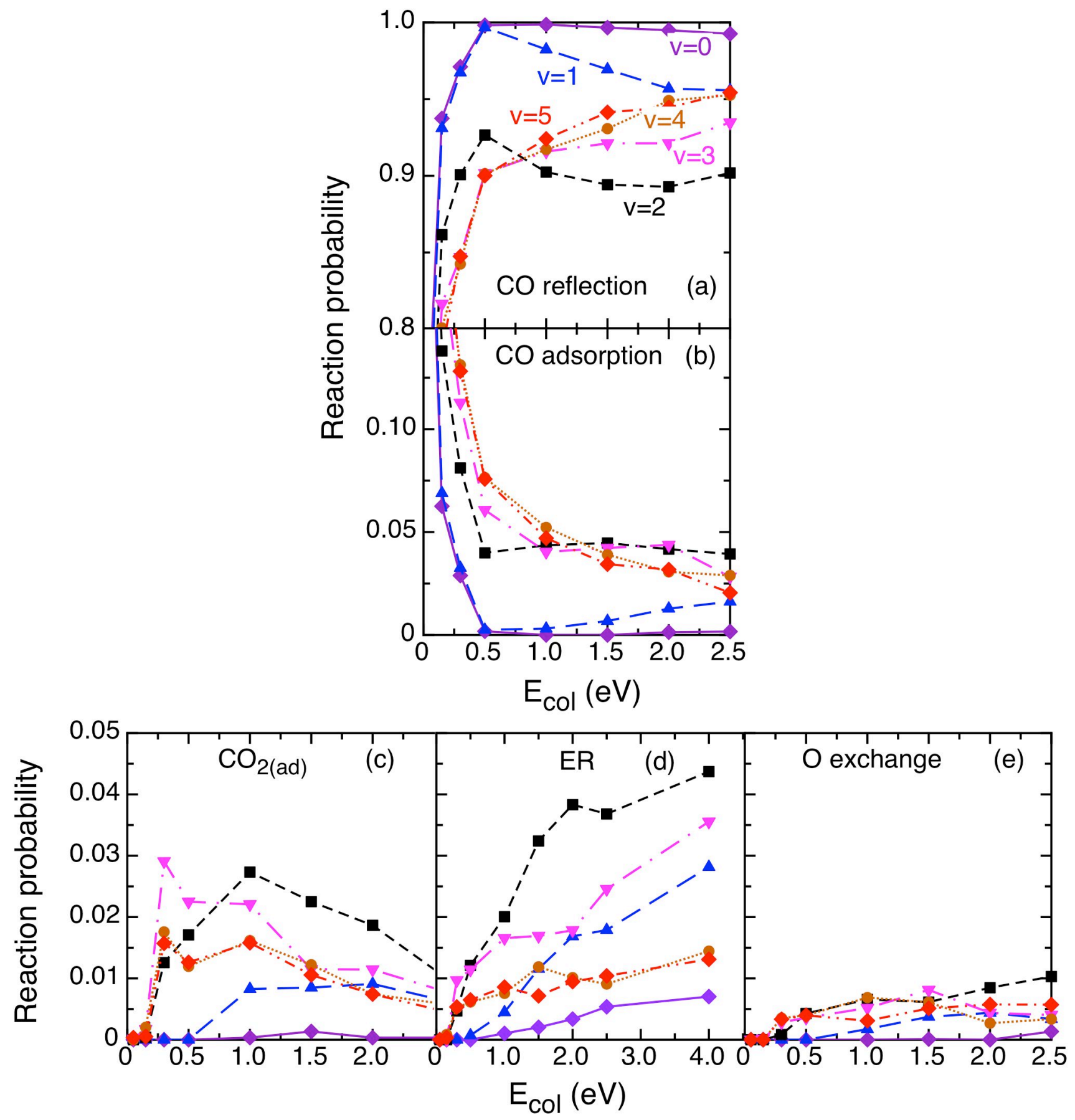
Fig. 5

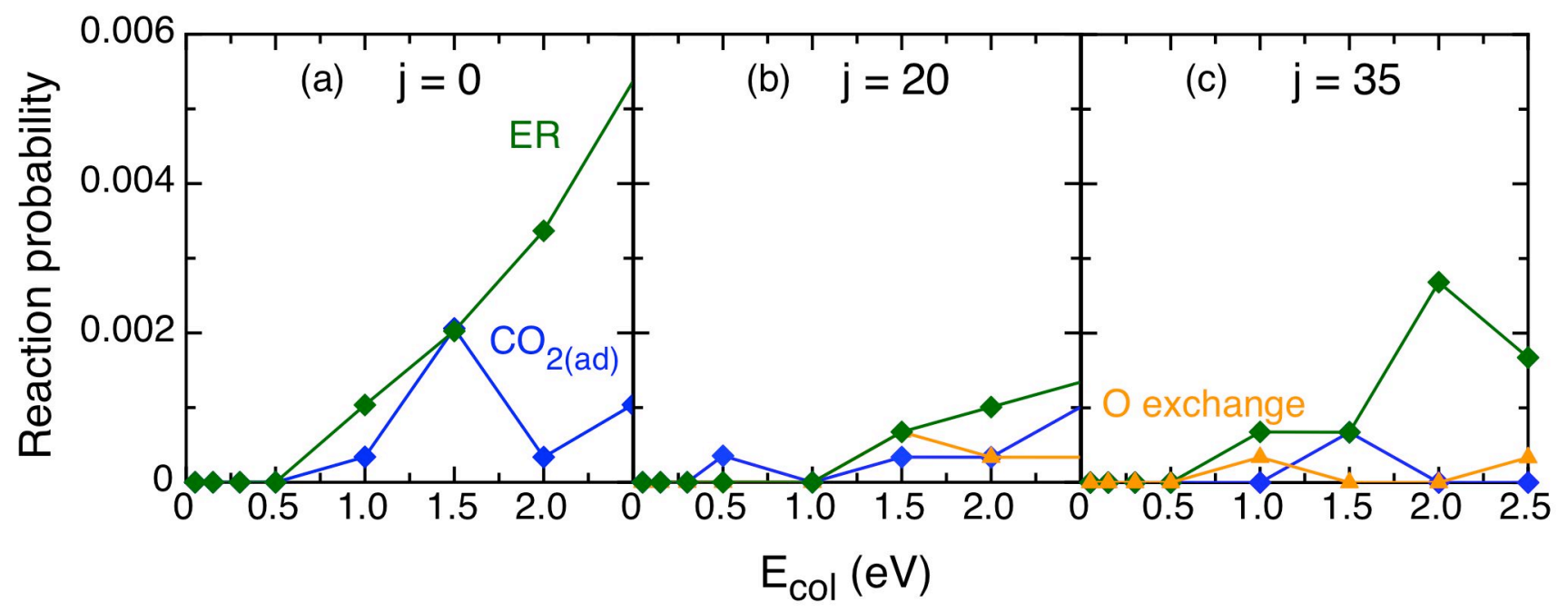


Fig. 6

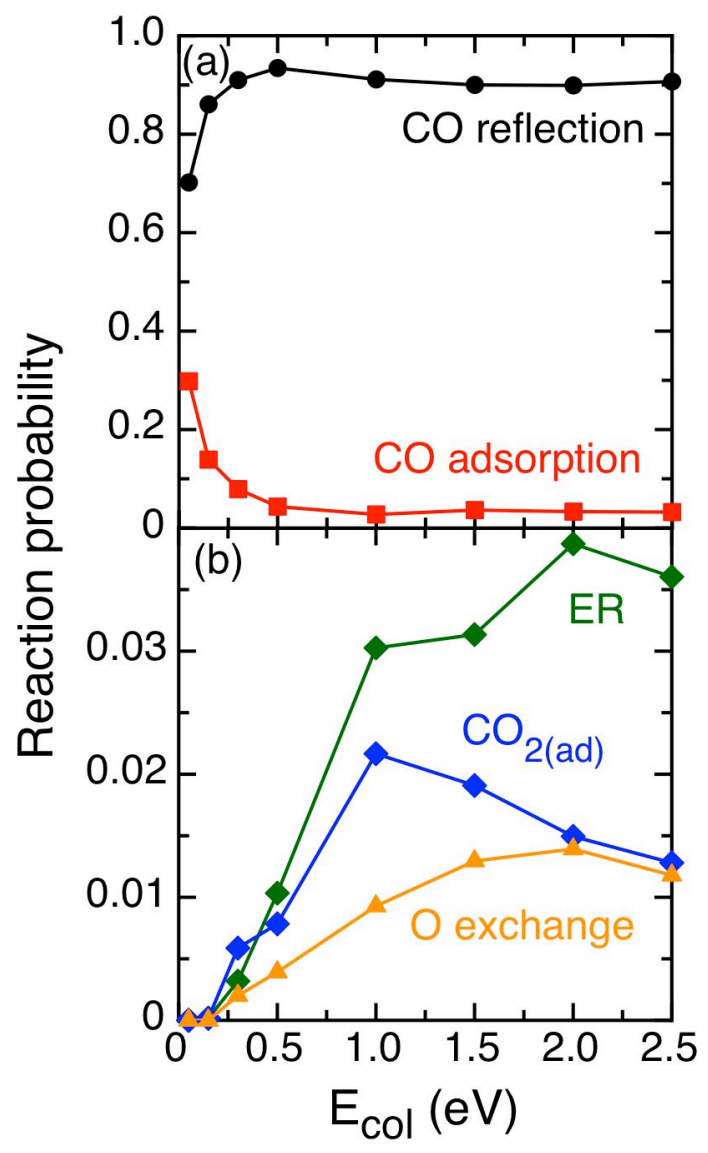


Fig. 7

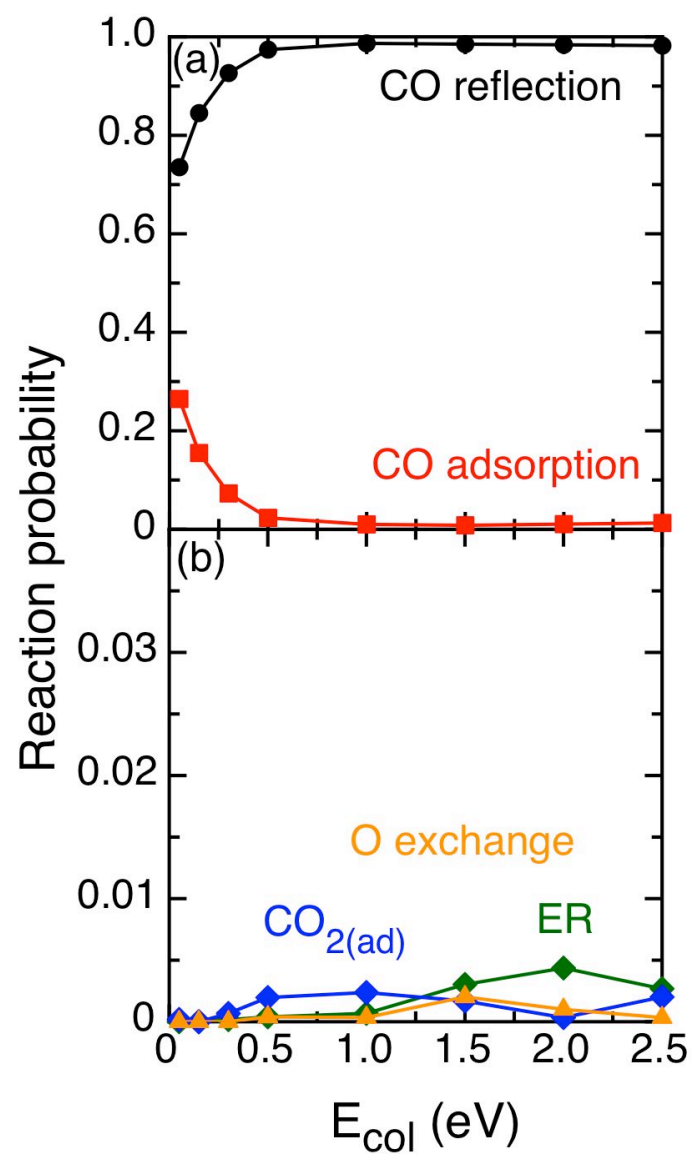


Fig. 8

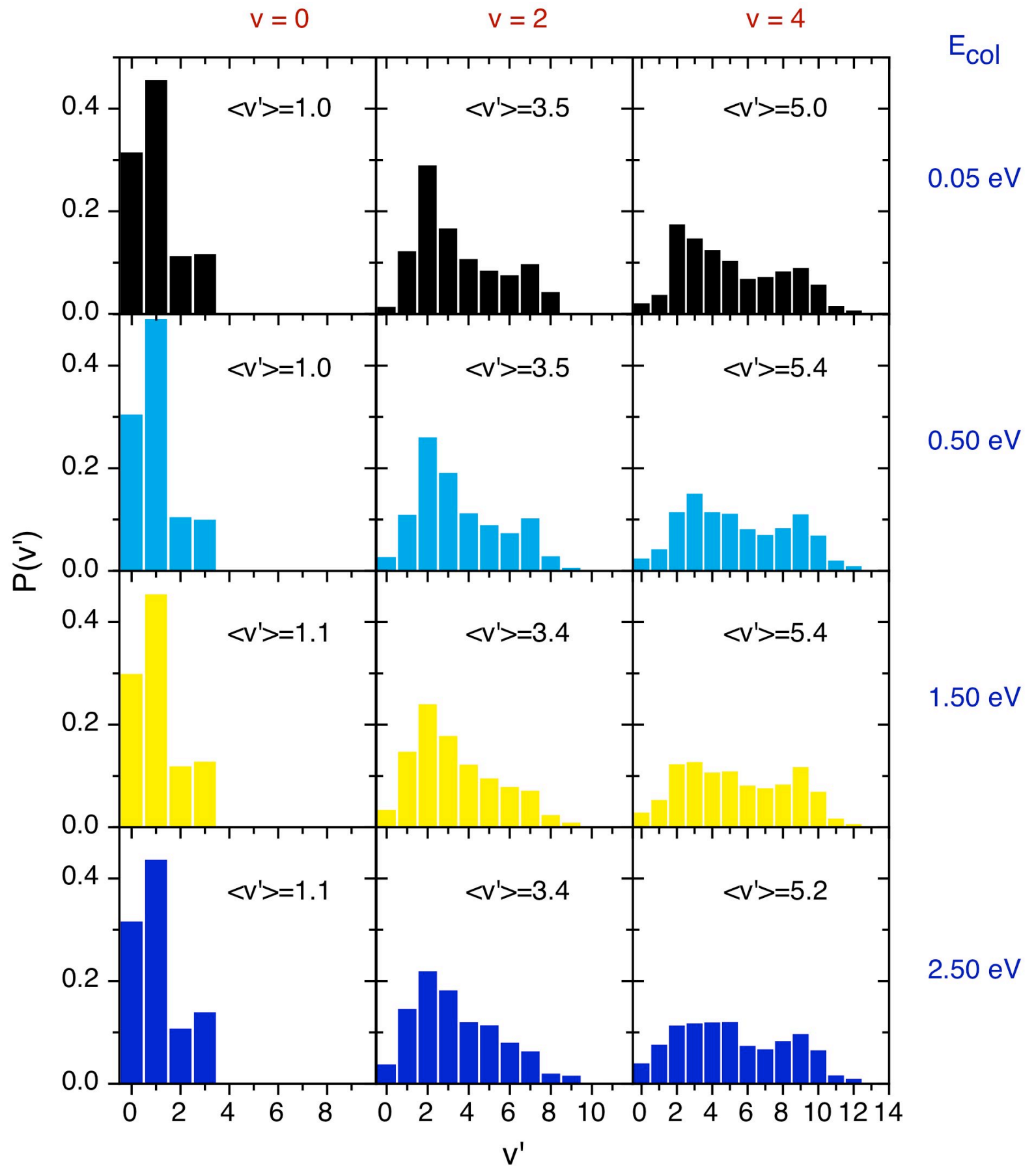


Fig. 9

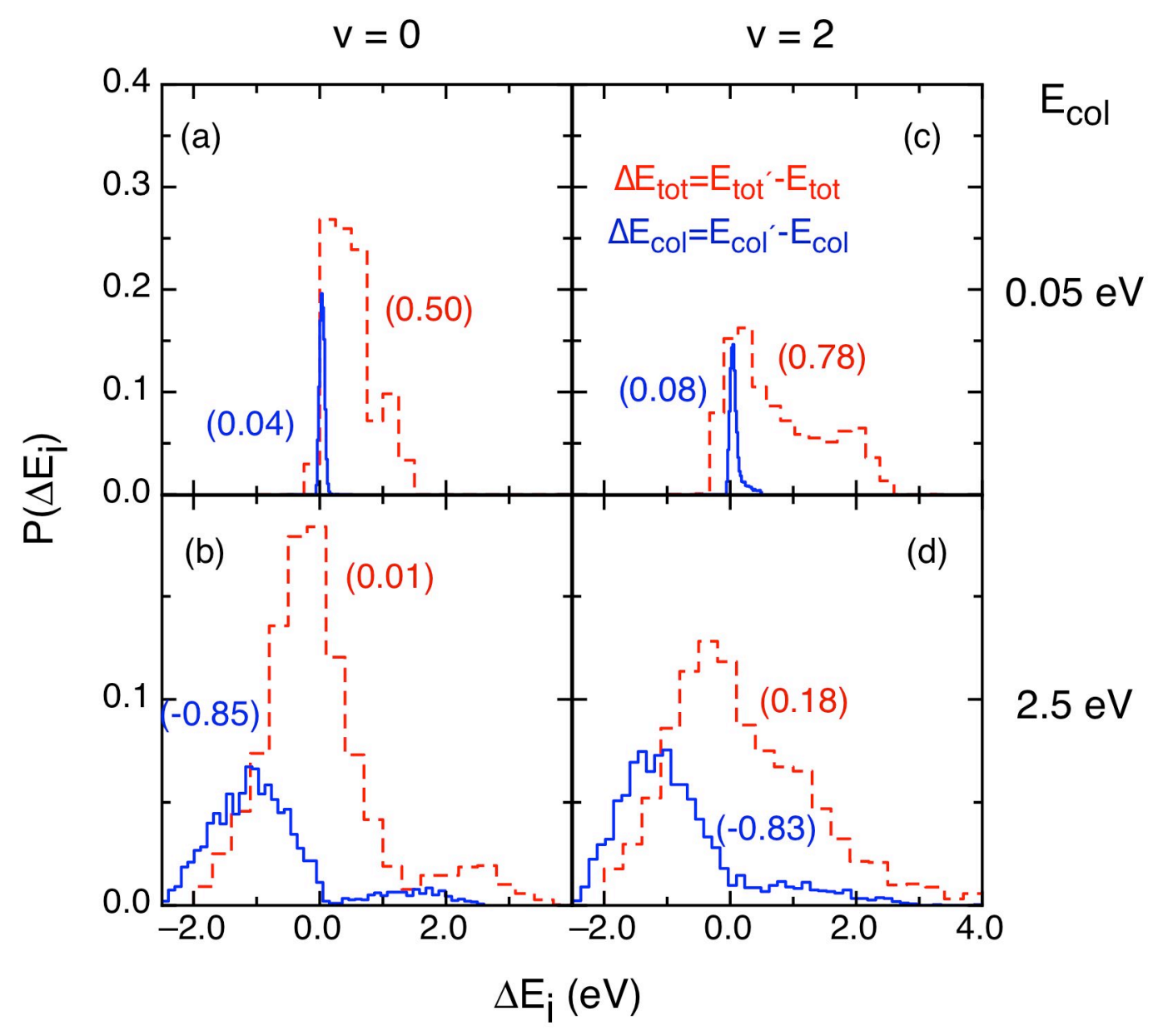




\section{References}

[1] Seiff A, Kirk DB (1977) J Geoph Research 82: 4364-4378

[2] Ngo T, Snyder EJ, Tong WM, Williams RS, Anderson MS (1994) Surf Sci Lett 314: L817-L822

[3] Kovalev, VL, Kolesnikov AF (2005) Fluid Dyn 40: 669-693

[4] Arasa C, Gamallo P, Sayós R (2005) J Phys Chem B 109:14954-14964

[5] Cacciatore M, Rutigliano M, Billing GD (1999) J Therm Heat Trans 13:195-203

[6] Morón V, Gamallo P, Martin-Gondre L, Crespos C, Larregaray P, Sayós R (2011) Phys Chem Chem Phys 13:17494-17504

[7] Kulkarni, AD, Truhlar DG, Srinivasan, SG, van Duin, ACT, Norman P, Schwartzentruber TE (2013) J Phys Chem C 117: 258-269

[8] Sepka S, Chen YK, Marschall J, Copeland RA (2000) J Ther heat Trans 14: 45-52

[9] Fajín JLC, Cordeiro NDS, Gomes JRB (2008) J Phys Chem C 112: 17291-17302

[10] Kizilkaya AC, Gracia JM, Niemantsverdriet JW (2010) J Phys Chem C 114: 21672-21680

[11] Lee J, Zhang Z, Deng X, Sorescu DC, Matranga C, Yates JT Jr (2011) J Phys Chem C 115: 4163-4167

[12] Morón V, Arasa C, Busnengo HF, Sayós R (2009) Surf Sci 603: 2742-2751

[13] Kresse G, Hafner J (1993) Phys Rev B 47: 558-561

[14] Kresse G, Hafner J (1994) Phys Rev B 49: 14251-14269

[15] Kresse G, Furthmüller, J. Comput. Mater. Sci. 1996, 6, 15-50

[16] Kresse, G.; Furthmüller J (1996) Phys Rev B 54: 11169-11186

[17] Hammer B, Hansen LB, Nørskov JK (1999) Phys Rev B 59: 7413-7421

[18] Blöchl PE (1994) Phys Rev B 50: 17953-17979

[19] Kresse G, Joubert D (1999) Phys Rev B 59: 1758-1775

[20] Monkhorst HJ, Pack JD (1976) Phys Rev B 13: 5188-5192

[21] Grimme S (2006) J Comput Chem 27: 1787-1799

[22] van Duin ACT, Dasgupta S, Lorant F, Goddard III WA (2001) J Comput Chem 105: 9396-9409

[23] Raju M, Kim SY, van Duin, ACT, Fichthorn, KA (2013) J Phys Chem C 17: 10558-10572

[24] Kim SY, Kumar N, Persson P, Sofo J, van Duin, ACT, Kubicki JD (2013) Langmuir 29: 7838-7846

[25] Neyts EC, Khalilov U, Pourtois G, van Duin ACT (2011) J Phys Chem C 115: 4818-4823

[26] Khalilov U, Neyts EC, Pourtois G, van Duin ACT, (2011) J Phys Chem C 115: 24839-24848 
[27] Khalilov U, Pourtois G, van Duin ACT, Neyts EC (2012) J Phys Chem C 116: 8649-8656

[28] Khalilov U, Pourtois G, van Duin ACT, Neyts EC (2012) J Phys Chem C 116: 21856-21863

[29] Ding J, Zhang Y, Han KL (2013) J Phys Chem A 117: 3266-3278

[30] Cheng XM, Wang QD, Li JQ, Wang JB, Li XY (2012) J Phys Chem A 116: 9811-9818

[31] Rahaman O, van Duin ACT, Bryantsev VS, Mueller JE, Solares SD, Goddard III, WA Doren DJ (2010) J Phys Chem A 114: 3556-3568

[32] Bai C, Liu L, Sun H (2012) J Phys Chem C 116: 7029-7039

[33] Pitman MC, van Duin ACT (2012) J Am Chem Soc 134: 3042-3053

[34] Norman P, Schwartzentruber TE, Leverentz H, Luo S, Meana-Pañeda R, Paukku Y, Truhlar DG (2013) J Phys Chem C 117: 9311-9321

[35] Khalilov U, Pourtois G, Huygh S, van Duin ACT, Neyts EC, Bogaerts A (2013) J Phys Chem C 117: 9819-9825

[36] Newsome AD, Sengupta D, Foroutan H, Russo MF, van Duin ACT (2012) J Phys Chem C 116 : 16111-16121

[37] Newsome AD, Sengupta D, van Duin ACT (2013) J Phys Chem C 117: 5014-5027

[38] Farah K, Müller-Plathe F, Böhm MC (2012) ChemPhysChem 13: 1127-1151

[39] Parsons N, Levin DA, van Duin ACT (2013) 138:044316-1-13

[40] Gamallo P, Martin-Gondre L, Sayós R, Crespos C, Larregaray P (2013) Potential energy surfaces for the dynamics of elementary gas-surface processes, In: Díez Muiño R, Busnengo HF (ed) Dynamics of gas-surface interactions: atomic-level understanding of scattering processes at surfaces, $1 \mathrm{rd}$ edn. Springer-Verlag, Berlin Heidelberg, pp 25-50

[41] Billing GD (2000) Dynamics of Molecule Surface Interactions. John Wiley \& Sons, New York, pp 93-111

[42] Garrison BJ (1992) Chem Soc Rev 21: 155-162

[43] Martinazzo R, Assoni S, Marinoni G (2004) J Chem Phys 120: 8761-8771

[44] Tully JC (1980) J Chem Phys 73: 1975-1985

[45] Arasa C, Busnengo HF, Salin A, Sayós R (2008) Surf Sci 602: 975-985

[46] QCTSURF code is not published. More information can be obtained from authors.

[47] Chase MW Jr (1998) NIST-JANAF thermochemical tables, J Phys Chem Ref Data Monograph 9, 4th edn. American Institute of Physics, New York

[48] Gray DE (ed) (1982) American Institute of of Physics Handbook, 3rd edn. McGraw-Hill, 
New York

[49] Fang W, Liu W. Guo X, Lu X, Lu L (2011) J Phys Chem C 115: 8622-8629

[50] Lee J, Zhang Z, Deng X, Sorescu DC, Matranga C, Yates Jr. JT (2011) J Phys Chem C 115: 4163-4167

[51] Fajín JLC, Cordeiro MNDS, Gomes JRB (2008) J Phys Chem C 112: 17291-17302

[52] Sorescu DC, Lee J, Al-Saidi WA, Jordan KD (2011) J Chem Phys 134: 104707-1-13

[53] Fang H, Kamakoti P, Zang J, Cundy S, Paur C, Ravikovitch PI, Sholl DS (2012) J Phys Chem C 116: 10692-10701

[54] Morón V, Arasa C, Sayós R, Busnengo HF (2008) AIP Conf Proc 1084: 682-687 